\title{
MEGAEVENTOS ESPORTIVOS: O DESENVOLVIMENTO DO LEGADO ESPORTIVO EDUCACIONAL
}

\author{
Andressa Peloi Bernabé \\ Universidade Estadual de Maringá, Maringá, Paraná, Brasil \\ Fernando Augusto Starepravo \\ Universidade Estadual de Maringá, Maringá, Paraná, Brasil
}

\begin{abstract}
Resumo
O presente estudo buscou explorar expectativas em relação aos legados esportivos educacionais dos Jogos Olímpicos e Paraolímpicos Rio 2016, e possíveis estratégias da Educação Física para garantir tais legados de forma positiva à população, especialmente a crianças e jovens que frequentam o ambiente escolar. Para atingir tal finalidade, uma intervenção de caráter experimental foi realizada com alunos do Programa ProJovem. Ao analisar a intervenção, concluímos que o desenvolvimento desse legado possui relevância por não ter abrangência e não ser do conhecimento dos alunos, na medida em que busca desenvolver uma cultura esportiva baseada na educação e nos valores olímpicos, pelo viés da Educação Física Escolar, que não se centra apenas na formação voltada ao alto rendimento.
\end{abstract}

Palavras chave: Megaeventos. Legados. Esporte. Educação Física.

\section{Introdução}

No Brasil, principalmente na atual década, verifica-se um aumento representativo dos estudos a respeito de megaeventos esportivos (RUBIO, 2007; VILLANO, TERRA, 2008; SANTIN, 2009; SOUZA, MARCHI JR., 2010; entre outros). Tal aumento deve-se, especialmente, à realização dos megaeventos esportivos que serão sediados no país, a Copa do Mundo de Futebol Masculino em 2014 e os Jogos Olímpicos e Paraolímpicos no Rio de Janeiro em 2016 (JO/PO Rio 2016).

Os megaeventos, bem como suas relações e conjunturas, são considerados "campo fértil de investigação de relações sociais complexas e paradoxais da sociedade moderna" (ALMEIDA; MEZZADRI; MARCHI JR., 
2009, p.181), sendo a Educação Física uma das áreas de intervenção. Congregados a ela, inúmeros fatores podem ser estudados abrangendo o turismo, a mídia, a educação, e uma infinidade de legados que os megaeventos podem estabelecer. Consideramos por legados, aspectos que resultam em possibilidades à população, tendo caráter de herança, como afirmam Villano e Terra (2008).

Dentre a literatura que discute o assunto (DACOSTA (2008); HORNE (2007); CAPELA (2006); RUBIO (2007); entre outros), megaeventos esportivos são caracterizados como eventos de alcance mundial, que necessitam de estrutura e financiamento para acontecer. A junção do prefixo "mega" justifica-se por serem eventos culturais e esportivos de porte colossal, grandes invenções criadas pelo avanço científico e tecnológico, resultantes do grande boom da globalização (ALMEIDA; MEZZADRI; MARCHI JR., 2009). Devido a tais características, a Copa do Mundo 2014 e os JO/PO Rio 2016 são considerados megaeventos.

Partindo desse entendimento, estabelecemos um recorte ao presente trabalho, pois nos debruçaremos especialmente nos JO/PO Rio 2016, devido ao maior número de modalidades esportivas que esse megaevento oferece, possibilitando maior variedade e expectativa de desenvolvimento dos legados esportivos educacionais ${ }^{1}$.

Quando se discute a temática dos legados de megaeventos esportivos, principalmente pela mídia, há uma centralidade em questões materiais relacionadas à infraestrutura. São considerados como prioridade legados materiais que demonstram somente uma preocupação estrutural. No campo científico também ocorrem discussões a respeito de legados materiais, de caráter econômico e estrutural (PREUSS, 2008; CORREA et al., 2008; RIBERO, 2008). No entanto, há iniciativas de buscar aspectos positivos dos megaeventos em relação aos legados imateriais, mas as publicações referentes a tais proposições ainda encontram-se escassas (FILGUEIRA (2008); HATZIDAKIS (2008); RUBIO (2008)).

Dentre os legados imateriais, destaca-se a contribuição dos megaeventos esportivos na educação, especialmente na Educação Física, por ser uma disciplina que trata diretamente de discussões acerca do esporte, práticas corporais e desenvolvimento físico.

\footnotetext{
1 Este conceito está relacionado com o desenvolvimento de uma cultura esportiva, desenvolvida especialmente a partir da escola. Com o objetivo de ir além dos legados estruturais e materiais que não podem ser disponibilizados a toda a população brasileira, apostamos em um legado de caráter imaterial, a ser desenvolvido com parcerias mútuas a curto, médio e longo prazo, antes, durante e após os JO/PO Rio 2016.
}

Pensar a Prática, Goiânia, v. 17, n. 2, p. 456-471, jan./mar. 2014 457 
De modo a contribuir com a discussão de legados dos megaeventos esportivos no Brasil, o Governo Federal lançou, através do Ministério do Esporte, os "Cadernos de Legados Rio 2016" (BRASIL, 2009). Nestes cadernos foram escolhidos dois eixos para nortear a discussão sobre os legados, sendo o primeiro "Inclusão social, juventude, esporte e educação", e o segundo "Regeneração urbana e meio ambiente". Dentre o primeiro eixo de legados, destacamos a ênfase nos legados imateriais, com a asseveração dos programas Segundo Tempo ${ }^{2}$ e Mais Educação ${ }^{3}$.

Estes programas seriam fortes aliados no desenvolvimento dos legados esportivos educacionais, todavia, não podem constituir-se como única estratégia para a disseminação deste legado, visto que não atingem todos os alunos da rede pública do país, tampouco alunos da rede privada de ensino.

Além do reconhecimento e ampliação desses programas do governo, como será assegurado o legado esportivo educacional dos JO/PO Rio 2016? Diante desse questionamento, o objetivo principal deste estudo é explorar expectativas em relação aos legados esportivos educacionais e possíveis estratégias da Educação Física para garantir tais legados de forma positiva à população, especialmente crianças e jovens que frequentam o ambiente escolar.

Em face dessa problematização, consideramos pertinente ao estudo a realização de uma intervenção, de caráter experimental, com o intuito de iniciar a discussão sobre o desenvolvimento do legado esportivo educacional. Desta forma, a intervenção foi realizada com 28 alunos do Programa ProJovem $^{4}$, com idade entre 13 e 17 anos, da cidade de Maringá - PR e de seu distrito Iguatemi. Os encontros ocorreram em dois dias com os alunos do ProJovem de Iguatemi (G1), e dois dias com os alunos do ProJovem de Maringá (G2), sendo realizadas quatro horas de intervenção em cada dia, contemplando, portanto, 16 horas totais.

2 Segundo Tempo, programa do governo federal, é destinado a democratizar o acesso à prática e à cultura do esporte educacional, prioritariamente aqueles que se encontram em áreas de vulnerabilidade social e regularmente matriculados na rede pública de ensino (BRASIL, 2011).

Programa Mais Educação. Disponível em: http://portal.mec.gov.br/index.php?Itemid=86\&id=12372\&option=com_content\&view $=$ article, acesso em 19 de Maio de 2010.

$4 \quad$ Projovem Adolescente é um serviço socioeducativo gerido pelo Ministério de Desenvolvimento Social e Combate a Fome (MDS), e coordenado pela SASC em parceria com entidades sociais. Disponível em: http://www2.maringa.pr.gov.br/sasc/?cod=noticias/12674, acesso em 20 de Julho de 2012.

Pensar a Prática, Goiânia, v. 17, n. 2, p. 456-471, jan./mar. 2014 458 
Em tal intervenção, os dados coletados foram descritos em diário de campo com notas detalhadas sobre as atividades desenvolvidas, falas dos alunos e registro das observações. Optamos por realizar o diário de campo como instrumento de coleta, pois, como afirma Gibbs (2009), este tipo de instrumento permite o registro das discussões, ideias, significados que os indivíduos pesquisados dão ao contexto vivenciado, bem como, demais informações pertinentes a posteriores análises.

A seguir, discutiremos estes dados, de modo a relatar e analisar as atividades desenvolvidas, estabelecendo um diálogo entre a literatura e as percepções dos pesquisadores.

\section{O desenvolvimento do legado esportivo educacional}

A fim de iniciar a discussão sobre megaeventos esportivos e desenvolvimento do legado esportivo educacional no ambiente escolar, realizamos a intervenção pedagógica em duas instituições em que o Programa ProJovem atua, oferecendo atividades e acompanhamento social e pedagógico no contra turno escolar a adolescentes e jovens.

No primeiro contato com os alunos apresentamos o tema megaeventos, e logo de início, os dois grupos - G1 e G2 - se demonstraram interessados. Uma primeira discussão foi iniciada para detectarmos o entendimento dos alunos sobre legados, Jogos Olímpicos e megaeventos esportivos. Jogos Olímpicos, segundo G1, são exemplos de megaeventos que "reúnem vários países que disputam entre si, que necessitam de grupos de pessoas que se unem para trabalharem juntos". Quanto à definição de legados, demonstraram certa dificuldade, entretanto, afirmaram que "está ligado a ganhar prêmios, relacionado ao que é lei - legal", ou, que reflete a povos, ou seja, "união de várias pessoas".

Diferentemente do primeiro grupo, os alunos do G2 reuniram-se para definir seu entendimento acerca dos termos. Quanto aos Jogos Olímpicos e aos megaeventos esportivos, evidenciaram o entendimento semelhante ao G1, provavelmente por serem temas cotidianamente utilizados pela mídia. Ao demonstrarem o que entendem sobre legados, afirmaram como sendo "opinião que fica, herança", "heranças importantes, algo que marcou, que fica de recordação, algo de muito valor".

Após esse momento, a discussão prosseguiu, de forma pontual, sobre os JO/PO Rio 2016 e suas relações com o legado esportivo educacional, por meio de uma atividade na qual os alunos discorreram sobre o tema. As opiniões apresentaram-se muito distintas entre os alunos. Tivemos aqueles que

Pensar a Prática, Goiânia, v. 17, n. 2, p. 456-471, jan./mar. 2014 459 
afirmaram: "o país só vai gastar dinheiro, em vez de melhorar a saúde e a educação para o povo"; "o Brasil não tem estrutura para isso". Outros apontaram aspectos positivos: "Esse evento vai ajudar o Brasil a se desenvolver mais", "vai ajudar a economia", "com isso ganhamos incentivos de esportes, e também mais conhecimentos".

De acordo com as falas e o entendimento dos alunos, podemos destacar distintas opiniões, favoráveis e contrárias à realização dos JO/PO Rio 2016. Porém, houve consenso em relação às possíveis melhorias estruturais e materiais no país, por ocorrência dos JO/PO Rio 2016. Eles evidenciaram, também, dificuldade em apontar fatores e possíveis legados imateriais, o que pode ser analisado se levarmos em conta a ênfase, por parte da mídia, nos fatores materiais, estruturais e econômicos dos JO/PO.

Nesse sentido, Souza e Marchi Júnior (2010) discorrem sobre a disseminação, nas diversas instâncias midiáticas, dos legados "econômicos" e "desenvolvimentistas", que buscam difundir a ideia de progresso econômico brasileiro, elevada em circunstância dos megaeventos esportivos que acontecerão no país. Os autores afirmam que as discussões do legado social do esporte, presentes nos projetos de candidatura, projetos de financiamento dos megaeventos esportivos, nas falas de agentes e instituições, garantem uma "vantagem simbólica e, especialmente, material" (SOUZA E MARCHI JÚNIOR, 2010, p.249), no sentido de utilizar a logomarca "legado social" para obter financiamentos e promoção em função dos megaeventos esportivos. Souza e Marchi Júnior (2010) concluem que o ponto mais lamentável desta lógica é o destino e uso inadequados dos recursos financiados ou arrecadados.

De forma a legitimar o legado esportivo educacional, buscamos priorizar a discussão sobre legado imaterial, para além do âmbito econômico, estrutural e material, de modo a suscitar, como afirmam Souza e Marchi Júnior (2010), o papel mobilizador do esporte associado a uma política de re-educação, afirmando-o como patrimônio cultural da humanidade em seu caráter polissêmico.

Após a realização das discussões iniciais, desenvolvemos com os alunos uma atividade de "tabuleiro humano", buscando discutir diversos assuntos a respeito dos Jogos Olímpicos, quais sejam: surgimento na Antiguidade; características e costumes da Grécia Antiga; restauração pelo Barão de Coubertin; configuração dos Jogos Olímpicos na atualidade. Em duas equipes, os alunos progrediam no tabuleiro de acordo com o número sorteado no dado. Em cada casa do tabuleiro havia uma palavra relacionada ao tema, devendo ser encontrada pelos alunos para prosseguirem o jogo. 
O intuito da atividade foi aproximar os alunos das palavras e termos relacionados à história dos Jogos Olímpicos, destacando o aspecto conceitual da intervenção da Educação Física Escolar, que, a nosso entender, deve priorizar o desenvolvimento integral do aluno.

Segundo Rubio (2009), o conceito de desenvolvimento integral se faz presente, dentro de uma perspectiva histórica, no mosaico do Olimpismo que tematiza a ideia de educação para Coubertin, buscando a formação em sua totalidade: "Dentro dessa perspectiva Coubertin já defendia ao final no século XIX a existência da Educação Física no ambiente escolar como disciplina obrigatória." (RUBIO, 2009, p. 76). Nesta abordagem, a Educação Física, apropriando-se do esporte como conteúdo e possibilidade de intervenção educacional, deve primar para a integração dos domínios sociais, biológicos e psicológicos, sem que haja fragmentação, bem como buscar dialogar com outras manifestações.

Concluindo a atividade, foi realizada uma exposição sobre o tema, discutindo: origem das Olimpíadas na Grécia Antiga; realização, provas e modalidades dos Jogos Olímpicos na era moderna; princípios do olimpismo e da Educação Olímpica. Os alunos contribuíram com o entendimento e com as palavras-chave do tabuleiro, bem como com a discussão sobre o conhecimento de modalidades atualmente disputadas nos JO/PO, onde expuseram esportes mais praticados em nosso país como o futebol, a natação, o atletismo, as lutas, o basquete e o vôlei.

Prosseguimos a intervenção com a apresentação de um vídeo ${ }^{5}$ no qual Kátia Rúbio - pesquisadora e professora da USP - discorre sobre Jogos Olímpicos e valores olímpicos. O vídeo foi escolhido para fomentar a discussão sobre valores olímpicos: inclusão; oportunização de participação; reconhecimento à regra e a construção desta; desenvolvimento humano; a busca pela excelência em dar o melhor de si; fair play, entre outros. A discussão prosseguiu tomando por base o desenvolvimento desses valores nas aulas de Educação Física - exemplificados por meio dos jogos e atividades relatados a seguir - de modo a contribuir com o desenvolvimento social, cognitivo e físico dos alunos.

Neste sentido, Betti e Zuliani (2002) ressaltam a tarefa da Educação Física de introduzir e integrar os alunos à cultura corporal de movimento, propiciando o desenvolvimento integral. Os autores afirmam que:

$5 \quad$ Vídeo que compõe o material didático presente no DVD Recreio nas Férias e os Valores Olímpicos, de 2010. Este projeto foi desenvolvido pelo Programa Segundo Tempo, do Ministério do Esporte do Brasil.

Pensar a Prática, Goiânia, v. 17, n. 2, p. 456-471, jan./mar. 2014 461 


\begin{abstract}
Para isso, não basta aprender habilidades motoras e desenvolver capacidades físicas, aprendizagem esta necessária, mas não suficiente. Se o aluno aprende os fundamentos técnicos e táticos de um esporte coletivo, precisa também aprender a organizar-se socialmente para praticálo, precisa compreender as regras como um elemento que torna o jogo possível (portanto é preciso também que aprenda a interpretar e aplicar as regras por si próprio), aprender a respeitar o adversário como um companheiro e não um inimigo, pois sem ele não há competição esportiva (BETTI; ZULIANI, 2002, p. 75).
\end{abstract}

Nesta discussão os alunos relataram conhecer os valores olímpicos, porém, afirmaram que os mesmos não são trabalhados no âmbito escolar e, portanto, eles não compreendiam como seria possível o desenvolvimento destes em uma aula de Educação Física. No sentido de exemplificar tal desenvolvimento foram realizados alguns jogos e atividades, a serem relatados a seguir.

O primeiro jogo desenvolvido foi o "Futsal dominantes contra dominados", sendo que uma equipe formulava regras para a outra. No começo do jogo os alunos reclamaram, pois as regras dificultavam suas ações. Mas, ao final, refletindo sobre a atividade e discutindo as ações de cada equipe em tentar superar o adversário, conseguiram entender que o objetivo era trabalhar com a posse da regra, o respeito e a formulação desta, bem como sua função em um determinado jogo ou esporte. Como afirma Stigger (2005), entre vários fatores que influenciaram o desenvolvimento do esporte no mundo, a regra é fator imprescindível, haja vista que sua utilização em caráter universal tornou o esporte uma linguagem internacional.

O jogo "Futsal vendado" ocorreu de acordo com as regras já conhecidas, porém em duplas, um como guia e outro vendado, onde apenas esse último jogava com a bola. Os alunos demonstraram empolgação com o jogo e ao final pararam para analisar o que haviam experimentado. Um deles afirmou: "todos deveriam passar por isso para sentir na pele como é não enxergar".

Outra atividade realizada foi o "Goalball", onde os alunos, em duas equipes, vendados e sentados em seu campo, recebiam a bola e tinham por objetivo lançar com as mãos a fim de realizar o gol. Como na atividade anterior, os alunos gostaram de realizá-la, mesmo considerando difícil por te-

Pensar a Prática, Goiânia, v. 17, n. 2, p. 456-471, jan./mar. 2014 462 
rem que utilizar principalmente a audição, sentido que é remetido a segundo plano caso tenham o sentido perfeito da visão.

Tais atividades foram escolhidas a fim de incutir na discussão a temática da inclusão, bem como proporcionar aos alunos experimentação e reconhecimento das dificuldades e limitações das deficiências. Esse seria um caminho para o desenvolvimento da inclusão, pois, deste modo, pode-se compreender como integrar alunos deficientes nas práticas comuns diárias, seja nas aulas de Educação Física ou em contextos do próprio dia a dia.

Consideramos a inclusão e a deficiência como temas transversais, pois, como afirmam Darido et. al (2001, p. 22), estes são "temas sociais emergentes, indicando-os como questões geradoras da realidade social e que, portanto, necessitam ser problematizados, criticados, refletidos e, possivelmente, encaminhados". Por conseguinte, tais temas possuem relevância e importância social, havendo a necessidade de serem trabalhados nas aulas de Educação Física.

A última atividade desenvolvida foi o "Rugby Adaptado". O jogo foi vivenciado tendo como objetivo passar a bola depois da linha determinada atravessando a quadra. A bola só poderia ser passada com as mãos, em linha diagonal para trás, entre os companheiros do mesmo time. Para impedir a progressão do adversário com a bola e evitar o gol, os alunos tocavam no colega adversário em posse da bola e este tinha que devolver a posse de bola para a outra equipe. Os alunos tiveram contato com uma vivência esportiva pouco desenvolvida e praticada no Brasil, e, por esse motivo, sentiram dificuldade em executá-la. Mas no decorrer da atividade, se acostumaram à complexidade exigida e solicitaram a continuação da mesma.

Para finalizar a intervenção, realizamos uma conversa com os alunos, de modo a apontar todos os pontos trabalhados como possibilidades metodológicas para um possível desenvolvimento do legado esportivo educacional em função da realização dos JO/PO Rio 2016. Apontamos, como sendo nossa finalidade, desenvolver o legado no sentido de formar uma cultura esportiva, não somente objetivando a formação de atletas, mas a formação de sujeitos, protagonistas conscientes, que entendam a importância da prática esportiva e das relações que permeiam os megaeventos esportivos.

Após este diálogo, os alunos realizaram uma síntese na forma de um pequeno texto, onde demonstraram sua opinião a respeito da realização dos JO/PO Rio 2016, impactos, legados e pontos considerados positivos e negativos em decorrência dessa realização.

No G1 destacaram-se as seguintes afirmações:

Pensar a Prática, Goiânia, v. 17, n. 2, p. 456-471, jan./mar. 2014 463 
Nas Olimpíadas de 2016 as escolas devem falar sobre quando e onde a Olimpíada surgiu, e também realizar jogos para as crianças e os jovens se interessarem mais por esse assunto, já que muitas pessoas não poderão ir ao Rio de Janeiro para assistir.

Vão ficar a história, os estádios, quadras para usufruirmos, vai gerar emprego, várias construções, também vão ficar os esportes que podem ser usados nas escolas como o futevôlei, atletismo, lutas, ginástica artística. Também vão ficar coisas boas e ruins. Para o país vai ficar os legados, o dinheiro, a estrutura. Pode ser feito projetos nas escolas para tirar as crianças da rua, os adolescentes das drogas, ensinar esportes às pessoas com a educação física, para os alunos se interessarem mais.

No Brasil irá ficar muitas coisas boas, pois com as novas construções de quadras, estádios e piscinas irá aumentar o movimento da população nacional e internacional... e poderá haver uma grande melhora na educação física, e com isso o Brasil fica rico em esporte e lazer.

A opinião dos alunos do $\mathrm{G} 2$ foi um pouco distinta, como podemos verificar em algumas falas:

Eu não gostaria que os Jogos Olímpicos fossem no Brasil, porque eu acho que com todo o dinheiro gasto com isso poderia ser usado para ajudar escolas, saúde e pessoas necessitadas. Porém por um lado, seria bom, pois o Brasil seria bem visto mundialmente, demonstrando que tem porte para suportar um megaevento esportivo. Também pode ser bom pelos valores e legados que podem ser desenvolvidos nas escolas, com aulas de Educação Física, como a inclusão, a ética, [...]

Penso que não deveria ser aqui, pois as Olimpíadas são um jeito de fazer com que as pessoas esqueçam os reais problemas que acontecem no Brasil. Mas por outro lado pode conscientizar pelo legado esportivo educacional as pessoas de que fazer esporte é muito importante... e os valores que ele pode deixar que as pessoas podem ser mais solidárias, ajudar as pessoas, ter paz com os outros. 


\begin{abstract}
Bom, na minha opinião, os Jogos Olímpicos é sim bom para o nosso país porque além de trazer bons benefícios para o país também mostra os exemplo de vitória e superação para os outros países. Depois que acabar os Jogos nós iremos ficar com muitos valores e benefícios como quadras, estádios, e valores com o esporte, ética, respeito, paz que são benefícios para a nossa vida podendo assim progredir e até ensinar o próximo.
\end{abstract}

Ao relatarem suas opiniões sobre a realização dos Jogos Olímpicos no Brasil e os possíveis legados, os alunos do G2 foram quase unânimes ao afirmarem que não concordam com o país sediar os JO/PO Rio 2016, devido ao enorme gasto necessário a essa realização. Já o G1 apresentou uma visão um pouco mais otimista, relatando aspectos positivos dos JO/PO. Ambos os grupos demonstraram que acreditam no desenvolvimento de legados importantes à população.

Ou seja, como síntese da intervenção, pudemos observar que os alunos em geral trazem consigo percepções prévias acerca dos megaeventos esportivos, especialmente dos Jogos Olímpicos, pautadas pela mídia. Portanto, essa percepção inicial se mostrou superficial e limitada, caracterizada como de senso comum.

Entendemos ser papel da escola e da Educação Física formar sujeitos críticos, reflexivos e que possam transcender o conhecimento do senso comum. Nesse sentido, as intervenções realizadas no âmbito escolar, pela Educação Física, podem aproveitar o momento de interesse crescente da sociedade nos megaeventos esportivos para aperfeiçoar a formação dos alunos, despertando a criticidade acerca de grandes eventos que envolvem toda a sociedade brasileira. E, além disso, formar cidadãos que compreendam os valores relacionados ao esporte e a importância da prática cotidiana e sistematizada do mesmo para sua qualidade de vida e desenvolvimento pessoal.

Ao final da intervenção, pudemos observar que os alunos demonstraram ter agregado mais conhecimentos em relação àquilo que trouxeram no início. Não obstante, houve um acréscimo de criticidade sobre o assunto, e um melhor entendimento dos sentidos e significados do esporte em nossa sociedade.

Por tudo isso, podemos afirmar que mesmo intervenções mais pontuais e abreviadas são de suma importância para que a Educação Física possa cumprir seu papel na formação dos alunos em espaços formais ou não for-

Pensar a Prática, Goiânia, v. 17, n. 2, p. 456-471, jan./mar. 2014 465 
mais, agregando um novo elemento que surge nesse início do século XXI a realização dos megaeventos esportivos no Brasil.

Pretendemos que a intervenção realizada possa ser um ponto de partida para outras ações, capitaneadas por professores de Educação Física e demais envolvidos com o esporte, nas mais distintas regiões do país, com vistas ao desenvolvimento de um efetivo e consistente legado esportivo educacional à população brasileira.

\section{Considerações Finais}

A realização dos Jogos Olímpicos e Paraolímpicos no Brasil em 2016, com sede na cidade do Rio de Janeiro, é fato irrefutável mediante os questionamentos a favor ou contra, sejam advindos da população em geral ou da comunidade acadêmica. No papel de comunidade acadêmica, entendemos que a Educação Física, por estar ligada de forma direta aos esportes e modalidades esportivas - ponto chave da realização dos Jogos - deve assegurar e contribuir com os futuros legados deste megaevento.

Se no campo dos legados materiais e estruturais há ampla abrangência pela mídia, o mesmo não ocorre no campo imaterial ou social e, quando este é citado, aparece focado na visão salvacionista do esporte. Por esta incoerência, o campo da Educação Física deve abranger meios para ampliar esta visão, incluindo um desenvolvimento de legado esportivo educacional que cerceia este objetivo de caráter imaterial.

A partir da análise das intervenções realizadas com os dois grupos do Programa ProJovem, entendemos que o desenvolvimento do legado esportivo educacional deve ser apropriado pela Educação Física Escolar. Quando questionados, antes das atividades e discussões realizadas, a respeito dos possíveis legados, os alunos demonstraram em suas falas uma influência da mídia, devido à consideração dos legados materiais.

Portanto, o desenvolvimento deste legado possui importância e relevância científica, na medida em que busca desenvolver uma cultura esportiva baseada na educação e nos valores olímpicos, que não se centra apenas na formação de atletas profissionais e sim numa formação integral dos alunos pelo viés da educação escolar, que pode atingir grande parcela da população brasileira.

Após a ida a campo, analisando as intervenções, nos deparamos com uma limitação em nossa ação, pois o período de oito horas não se mostrou totalmente suficiente para abarcar por completo os aspectos relacionados ao

Pensar a Prática, Goiânia, v. 17, n. 2, p. 456-471, jan./mar. 2014 466 
legado esportivo educacional. Fato que aponta para a necessidade de novas pesquisas e estudos sobre a temática.

Porém, este estudo possui sua relevância no sentido de apontar o desenvolvimento do legado em questão por meio da Educação Física Escolar, pois os alunos se mostraram motivados com o tema e abertos a novos conhecimentos. Neste ponto, destacamos o poder de atração que o esporte tem como estratégia de intervenção, aliado ao fato de que a realização dos JO/PO Rio 2016 captará a atenção da população. Mediante a inevitabilidade destes fatos, a Educação Física deve usufruir destes megaeventos como mecanismos para atrair a atenção e o interesse dos alunos, buscando utilizar a mídia como aliada e transcendendo para um entendimento mais refinado e aprofundado, a fim de desenvolver nos alunos a identificação, consciência e criticidade acerca deste tema. Para além da Educação Física, o desenvolvimento do legado esportivo educacional também pode ser garantido por demais envolvidos com o esporte, como instituições, agentes, lideranças, entre outros.

\title{
MEGA SPORTING EVENTS: DEVELOPMENT OF EDUCATIONAL SPORTING LEGACY
}

\begin{abstract}
The present study sought to explore expectations of educational sporting legacy of the Olympic and Paralympic Games Rio 2016, and possible strategies of Physical Education to ensure such a positive legacy for the population, especially children and young people who attend the school environment. To achieve this purpose, an intervention of a trial was conducted with students ProJovem Program. In reviewing the intervention, we conclude that the development of this legacy has relevance, for not having coverage and not be aware of the students, in that it seeks to develop a sporting culture, based on Olympic values education and the bias of physical education, not only focuses on training focused on high performance.
\end{abstract}

Keywords: Mega Events. Legacies. Sport. Physical Education.

\section{MEGA-EVENTOS DEPORTIVOS: DESARROLLO DEL LEGADO DEPORTIVO EDUCATIVO}

Resumen

El presente estudio trata de explorar las expectativas de legado deportivo educativo de los Juegos Olímpicos y los Juegos Paralímpicos Río 2016, y las posibles

Pensar a Prática, Goiânia, v. 17, n. 2, p. 456-471, jan./mar. 2014 467 
estrategias de educación física para garantizar un legado positivo para la población, especialmente los niños y jóvenes que asisten al ambiente escolar. Para lograr este fin, la intervención de un ensayo se realizó con el programa ProJovem estudiantes. En la revisión de la intervención, se concluye que el desarrollo de este legado tiene relevancia, por no tener cobertura y no tener conocimiento de los alumnos, ya que busca desarrollar una cultura deportiva, basada en la educación en valores olímpicos y el sesgo de la educación física, no sólo se centra en la capacitación se centró en el alto rendimiento.

Palabras-claves: Mega-Eventos. Legados. Deporte. Educación Física

\section{Referências}

ALMEIDA, B. S.; MEZZADRI, F. M.; MARCHI JR., W. Considerações sociais e simbólicas sobre sedes de megaeventos esportivos. In: Dossiê 20072016 - A Década dos Megaeventos Esportivos no Brasil. Motrivivência, ano XXI, n. 32/33, p. 178-192, jun/dez. de 2009.

BRASIL. Ministério da Educação. Mais Educação. Disponível em: <http://portal.mec.gov.br/index.php?Itemid=86\&id=12372\&option=com_co ntent\&view $=$ article $>$. Acesso em: 19 de maio de 2010.

. Ministério do Desenvolvimento Social e Combate à Fome. Projo-
$\begin{aligned} & \text { vem } \\ & \text { adolescente. }\end{aligned}$
<http://www.mds.gov.br/falemds/perguntas-frequentes/assistencia-
social/psb-protecao-especial-basica/projovem-adolescente-15-a-17-
anos/projovem-adolescente-institucional>. Acesso em: 20 de julho de 2012.

. Ministério do Esporte. Caderno de Legados. 2009. Disponível em: < http://www.esporte.gov.br/snear/rio2016/ > . Acesso em: 22 de agosto de 2011.

Diretrizes do Programa Segundo Tempo. Brasília, 2011.

BETTI, M.; ZULIANI, L. R. Educação física escolar: uma proposta de diretrizes pedagógicas. Revista Mackenzie de Educação Física e Esporte n.1, v. 1, p. 73-81, 2002. Disponível em: http://editorarevistas.mackenzie.br/index.php/remef/article/view/1364/1067. Acesso em: 30 de maio de 2013. 
CAPELA, P. R. C. Os mega-eventos esportivos e as políticas públicas de esporte e lazer de resistência. Motrivivência, Ano XVIII, n. 27, p. 101-116, dez 2006.

CORRÊA, D. et al. Convergências do Tema Legados Esportivos. In: DaCOSTA, L. P. et al. (Ed.). Legados de Megaeventos Esportivos. Brasília: Ministério do Esporte, p. 47- 52, 2008.

DaCOSTA, L. P. et al. (Ed.). Legados de Megaeventos Esportivos. Brasília: Ministério do Esporte, 2008.

DARIDO, S. C. et al. A educação física, a formação do cidadão e os parâmetros curriculares nacionais. Revista Paulista de Educação Física, v. 15, n. $1, \quad$ p. 17-32, 2001. Disponível em: http://www.cief.com.br/arquivoupnuefem/formacao.pdf. Acesso em: 16 de maio de 2013.

FILGUEIRA, J. C. M. Importância dos legados de megaeventos esportivos para a Política Nacional do Esporte - Cidade, Cidadania e Direitos dos Cidadãos. In: DaCOSTA, L. P. et al. (Ed.). Legados de Megaeventos Esportivos. Brasília: Ministério do Esporte, p. 65-73, 2008.

GIBBS, G. Análise de dados qualitativos. Porto Alegre: Artmed, 2009.

HATZIDAKIS. G. S. Legado educacional dos Jogos Pan-Americanos e dos Jogos Parapan 2007: instrumentalizando a escola. In: DaCOSTA, L. P. et al. (Ed.). Legados de Megaeventos Esportivos. Brasília: Ministério do Esporte, p. 395-402, 2008.

HORNE, J. The Four 'Knowns' of Sports Mega-Events. Leisure Studies, v. 26, n. 1, jan, p. 81-96, 2007.

PREUSS, $\mathrm{H}$. Tendências atuais de conhecimento sobre gestão e economia de megaeventos e legados esportivos. In: DACOSTA, L. et al. (ed.). Legados de Megaeventos Esportivos. Brasília: Ministério dos Esportes, 2008.

RIBEIRO, F. T. Legado de Megaeventos Esportivos Sustentáveis: a importância das instalações esportivas. In: DaCOSTA, L. P. et al. (Ed.). Legados 
de Megaeventos Esportivos. Brasília: Ministério do Esporte, p. 107- 116, 2008 .

RUBIO, K. (org). Megaeventos esportivos, legados e responsabilidade social. São Paulo: Casa do Psicólogo, 2007.

RUBIO, K. O Legado heróico do papel social do atleta. In: DACOSTA, L. et al. (ed.). Legados de Megaeventos Esportivos. Brasília: Ministério dos Esportes, p. 217-226, 2008.

O legado educativo dos megaeventos esportivos. In: Dossiê 20072016 - A Década dos Megaeventos Esportivos no Brasil, Motrivivência, ano XXI, n. 32/33, p. 71-88, jun/dez de 2009.

. Recreio nas Férias - DVD de Capacitação 2 - Valores Olímpicos. Programa Segundo Tempo, 2010.

SANTIN, S. Megaeventos Esportivos no Brasil: Benefícios - Contradições. In: Dossiê 2007-2016 - A Década dos Megaeventos Esportivos no Brasil. Motrivivência, ano XXI, n. 32/33, p. 71-88, jun/dez de 2009.

SOUZA, J.; MARCHI JÚNIOR, W. Os "legados" dos megaeventos esportivos no Brasil: algumas notas e reflexões. Motrivivência, ano XXII, n. 34, p. 245-256, jun. de 2010.

STIGGER, M. P. Educação Física, esporte e diversidade. Autores Associados, 2005.

VILLANO, B.; TERRA, R. Definindo a Temática de Legados de Megaeventos Esportivos. In: DACOSTA et al. Legado de Megaeventos Esportivos. Brasília: Ministério do Esporte, p. 103-106, 2008.

Recebido em: 05/07/2013

Revisado em: 14/08/2013

Aprovado em: 14/08/2013

Endereço para correspondência:

andressa.bernabe@hotmail.com

Andressa Peloi Bernabé

Pensar a Prática, Goiânia, v. 17, n. 2, p. 456-471, jan./mar. 2014 470 
Universidade Estadual de Maringá, Centro de Ciencias da Saude, Departamento de Educação Física.

Av. Colombo, 5790

Jardim Universitário

87020-900 - Maringa, PR - Brasil

Pensar a Prática, Goiânia, v. 17, n. 2, p. 456-471, jan./mar. 2014 